\title{
Effects of Two Dental Whitening Strips on Dental Sensitivity and Gingival Health
}

\section{Angel Emmanuel Rodriguez ${ }^{1^{*}}$, Janet Ajdaharian ${ }^{2}$}

${ }^{1}$ DDS, MSD, 120 South Spalding Drive, Suite 201, Beverly Hills 90212, CA, USA

${ }^{2}$ Researcher/project administrator, 436 N. Roxbury Drive, Suite 202, Beverly Hills 90210, CA, USA

\begin{abstract}
Aims: The aim of this study was to evaluate the in-vivo effects of a novel whitening strip on tooth sensitivity and gingival irritation.

Methods: A total of 10 participants were simultaneously recruited to apply one brand of whitening strips to the upper left and lower right quadrant of the mouth and the other brand to the remaining teeth daily for a period of 30 mins over 10 consecutive days. Tooth sensitivity and gingival irritation were evaluated for each tooth at baseline, day 5 and day 10 by a blinded clinician, using a $3 \mathrm{sec}$ air spray test on each isolated tooth to semi-quantify sensitivity (Likert scale, $0-4$ ), and visual inspection to identify gingival irritation (0-3). Each participant completed a questionnaire daily after each whitening treatment and documented the following parameters: (1) dental sensitivity for each tooth (Yes/No) and (2) gingival irritation for each tooth (Yes/No). Data were analyzed using ANOVA techniques.
\end{abstract}

Results: : For the office-based evaluations, significantly lower gingival irritation resulted from use of the test Oral Essentials ${ }^{\circledR}$ Whitening Strips compared to the control Crest ${ }^{\circledR}$ 3D WHITE ${ }^{\text {TM }}$ Whitestrips. Patient self-evaluations recorded lower gingival irritation, although not at a significant level, after the use of the test strips compared to the control strips. Dental sensitivity was comparable in the two treatment groups as evaluated in home and in the dental office.

Conclusions: Use of a novel tooth whitening strip resulted in less gingival irritation compared to a widely used control whitening strip.

Keywords: Tooth whitening; Gingival irritation; Dental sensitivity; Whitening strips

\section{Introduction}

Brightening discolored teeth is a very common procedure in dental offices, mainly for esthetic reasons [1]. Tooth staining can have many etiologies, including extrinsic factors such as the consumption of tea, coffee, and cigarettes, and intrinsic causes such as tetracycline, trauma, root resorption, enamel hypoplasia and aging. Also, caries and ill-matched or deteriorated restorations may adversely affect tooth color. External pigments can either be adsorbed into the dental pellicle or remain on the surface of the tooth, resulting in color changes [2,3].

Tooth bleaching is considered routine treatment in $91 \%$ of dental offices, with a reported success rate of $79 \%$ [4]. Bleaching agents primarily contain hydrogen peroxide or carbamide peroxide, which breaks down to produce hydrogen peroxide $[5,6]$. Unstable free radicals are released when they contact a biological material such as saliva or enamel [7]. These free radicals oxidize large pigment or stain molecules, changing tooth color by altering the chemical structure of the organic substance of the enamel and dentine [8].

Currently, there are three commercially available categories of bleaching agents: in-office, in-home and over-the-counter formulations with different concentrations of the active ingredients [9]. Currently $10 \%$ carbamide peroxide is the only product approved by the American Dental Association (ADA), as a safe and efficient product for in-home bleaching procedures [10].

Over the counter bleaching agents are available in a wide range of formulations including whitening rinses, tray-based tooth whiteners, whitening strips and gels [10]. Hydrogen peroxide -based whitening strips have been commercially available since 2000 . Their popularity is a result of their effectiveness, convenience of application, accessibility, ease of application and low cost $[11,12]$. However, safety and compatibility concerns have been raised due to the biotoxicity of the $\mathrm{HO}$ free radicals that are released to the target sites. Potential side effects include alteration of the enamel surface, gingival irritation, dental sensitivity and degeneration of the dental pulp [13]. The intensity of such side effects can vary depending on the concentration of the hydrogen peroxide used, treatment duration and the non-bleach composition of the product used [2]. In general, $50 \%$ of people may experience temporary tooth sensitivity as a result of tooth bleaching [13]. However, adverse effects increase with the greater concentration, duration and frequency of use of the bleaching agent [7]. Moreover, increased risk of adverse effects risk has been correlated with inappropriate or misuse of such bleaching products [12]. Although bleaching agent contact with the gingiva is undesirable, it can readily occur during home bleaching, especially when strips are applied [13]. Goal of this study was to evaluate in-vivo the effects of a novel tooth whitening strip on dental sensitivity and gingival irritation.

\section{Materials and Methods}

\section{Overview}

A total of 10 participants simultaneously applied one brand of

*Corresponding author: Angel Emmanuel Rodriguez, DDS, MSD, 120 South Spalding Drive, Suite 201, Beverly Hills-90210, CA, USA, Tel: +49 711 - 4400952; Email: angelrdzp@gmail.com

Received July 31, 2017; Accepted September 01, 2017; Published September 08, 2017

Citation: Rodriguez AE, Ajdaharian J (2017) Effects of Two Dental Whitening Strips on Dental Sensitivity and Gingival Health. Dentistry 7: 451. doi:10.4172/21611122.1000451

Copyright: (c) 2017 Rodriguez AE, et al. This is an open-access article distributed under the terms of the Creative Commons Attribution License, which permits unrestricted use, distribution, and reproduction in any medium, provided the original author and source are credited. 
whitening strip to the upper left and lower right quadrant of the mouth, and the other brand of whitening strip to the remaining teeth daily for a period of 30 mins for 10 consecutive days. Each participant filled out a questionnaire daily after each treatment and document (1) any sensitivity for each tooth (Yes/No: 1/0) and (2) gingival irritation for each tooth (Yes/No: 1/0). From this log, a cumulative score was calculated for sensitivity and gingival irritation for each tooth unit. Additionally, tooth sensitivity and gingival irritation were evaluated in-office for each tooth at baseline, day 5 and day 10 by a blinded, prestandardized dentist with more than 25 years of clinical experience, using a $3 \mathrm{sec}$ air spray test on each isolated tooth to semi-quantify sensitivity (Likert scale, $0-4$ ), and visual inspection to identify gingival irritation (0-3 (none, mild, moderate, severe)). This study had only one leg. Subjects were provided with a new Oral B ${ }^{\circledR}$ (Procter \& Gamble Company, Cincinnati, OH 45202) toothbrush and Crest ${ }^{\oplus}$ Pro-Health $^{\circ}$ (Procter \& Gamble Company, Cincinnati, $\mathrm{OH}$ 45202) toothpaste at the beginning of the study and were instructed not to use any other mouthwash or toothpaste during the study.

\section{Subjects}

All subjects signed an informed consent form prior to enrollment in this study. Subjects consisted of 10 healthy volunteers age 18-45 (mean 29.4 years).

\section{Inclusion Criteria}

- <16 clinically and radiographically healthy teeth as defined by clinical examination by 1 dentist with $>20$ years clinical experience

- Löe and Silness Gingival Index $<1$

- all pocket depths $\leq 4 \mathrm{~mm}$

\section{Exclusion Criteria}

- any known history of allergy to personal care/consumer products or their ingredients

- or any ingredients in the products used

- any medical condition which requires pre-medication prior to dental procedures

- diseases of the soft or hard oral tissues

- gingival recession $>2 \mathrm{~mm}$

- dental sensitivity to temperature change or pressure

- active or untreated caries lesions

- history of any systemic disease that could result in being immune compromised or delayed wound healing, and

- use of antibiotics within 3 months

- known history of hepatitis, HIV, ulcer forming diseases, abscesses, granulomas

- smokers and neither

- pregnant

- lactating

\section{Protocol}

After enrollment in the study, each subject received 40 identically packaged, coded whitening strips, 20 of which were test whitening strips (Oral Essentials ${ }^{\circledR}$ Whitening Strip, Beverly Hills, CA 90210) and
20 control whitening strips (Crest ${ }^{\bullet} 3 \mathrm{D}$ WHITE ${ }^{\mathrm{me}}$ Whitestrips $^{\mathrm{mm}}$, Procter \& Gamble Company, Cincinnati, OH 45202). During the study period, subjects brushed their teeth twice daily and abstained from all other oral hygiene measures. Subjects placed the whitening strips on the designated quadrants for 30 minutes per day followed by thorough rinsing with water to remove any residue. They were instructed to wait at least 22 hours before each subsequent application. After each daily application, subjects completed a standardized log that was provided and checked by the dental office at each visit to document tooth sensitivity and gingival irritation.

This was a routine double-blinded, randomized study, with neither subjects, nor clinicians, or any other members of the study aware of specific product allocation sites or treatment status of the samples.

\section{Primary endpoints}

Data collection: In office: Day 0: baseline exam, photograph of teeth and gingiva, sensitivity testing with $3 \mathrm{sec}$ blast of air for each tooth (0-4), documentation of gingival irritation status (0-3).

Day 5: photograph of teeth and gingiva, sensitivity testing with 3 sec blast of air for each tooth (0-4), documentation of gingival irritation status (0-3).

Day 10: photograph of teeth and gingiva, sensitivity testing with 3 sec blast of air for each tooth (0-4), documentation of gingival irritation status $(0-3)$.

All testing was performed by the same blinded pre-standardized examiner, a dentist with more than 20 years of clinical experience.

In home: Daily: Sensitivity (Y/N per tooth); Gingival irritation (Y/N per tooth).

Data analysis: All data were analyzed using individual tooth units and two-way ANOVA with Bonferroni correction for multiple measures.

\section{Results}

A total of 286 teeth were evaluated in 10 subjects. All subjects completed the study in full compliance with the protocol, as documented through in-home daily logs and in-office questionnaires at each visit.

\section{Office-based evaluation}

A significant overall difference was determined between the two treatment groups with regard to gingival irritation, (Figure 1) and between treatment effects on specific days of the treatment period $(\mathrm{P}<0.05$, Table 1$)$.

Our results show no significant difference in the effects of the two treatments on dental sensitivity overall (Figure 2) or on any specific treatment day $(1, \mathrm{P}>0.05$, Table 2$)$.

\section{Patient self-evaluation}

No significant difference was determined between the effects of the 2 whitening strips on gingival irritation (Figure 3 ) as scored by patients at home $(\mathrm{P}>0.05$, Table 3$)$.

The home-based sensitivity (Figure 4) scores were lower for the test strip than the control, however the difference was not significant $(\mathrm{P}>0.05$, Table 4$)$.

The home-based sensitivity (Figure 4) scores were lower for the test strip than the control, however the difference was not significant 
Citation: Rodriguez AE, Ajdaharian J (2017) Effects of Two Dental Whitening Strips on Dental Sensitivity and Gingival Health. Dentistry 7: 451. doi:10.4172/2161-1122.1000451

\begin{tabular}{|c|c|c|c|}
\hline & Day 0 & Day 5 & Day 10 \\
\hline Crest $^{\circledR}$ & $0.2 \pm 0.042$ & $1.8 \pm 0.170$ & $2.1 \pm 0.247$ \\
\hline Oral Essentials $^{\circledR}$ & $0.2 \pm 0.024$ & $0.7 \pm 0.082$ & $0.8 \pm 0.092$ \\
\hline
\end{tabular}

Table 1: Office-based mean scores of gingival irritation following treatment with Test or Control strips on Days 0, 5 and 10. Data are presented as mean \pm S.D.

\begin{tabular}{|c|c|c|c|}
\hline & Day 0 & Day 5 & Day 10 \\
\hline Crest $^{\circledR}$ & $0.30 \pm 0.048$ & $1.10 \pm 0.159$ & $1.20 \pm 0.150$ \\
\hline Oral Essentials $^{\circledR}$ & $0.50 \pm 0.085$ & $1.00 \pm 0.141$ & $0.63 \pm 0.108$ \\
\hline
\end{tabular}

Table 2: Office-based mean scores of tooth sensitivity following treament with Test or Control strips on Days 0,5 and 10. Data are presented as mean \pm S.D.

\begin{tabular}{|c|c|c|}
\hline & Crest $^{\circledR}$ & Oral Essentials $^{\circledR}$ \\
\hline Mean & $1.70+0.41$ & $0.80+0.29$ \\
\hline
\end{tabular}

Table 3: Mean self-assessed home-based scores of gingival irritation following treatment with Test or Control strips for 10 days.

\begin{tabular}{|c|c|c|}
\hline & Crest $^{\circledR}$ & Oral Essentials $^{\circledR}$ \\
\hline Mean & $0.35+0.16$ & $0.30+0.17$ \\
\hline
\end{tabular}

Table 4: Mean self-assessed home-based scores of tooth sensitivity following treatment with Test or Control strips for 10 days.

$(\mathrm{P}>0.05$, Table 4).

\section{Discussion}

Participants used the whitening strips for 30 minutes per day. Results were obtained in office at three time points: baseline, after 5 days and after 10 days. In addition, patients were asked to complete a questionnaire every day.

In this study, the adverse effects and symptoms often associated with tooth whitening were evaluated by a blinded in-office evaluator, and by the patients themselves. While the results differed somewhat between the 2 evaluation modalities, overall the test strips performed somewhat better than the control strips. In-office data documented significantly reduced gingival irritation, whereas self-evaluations determined somewhat lower (but not at a significant level) mean sensitivity resulting from use of the test strips as compared to the current gold standard treatment.

The side effects of bleaching agents on oral tissues have been studied extensively. Whitening strips have been widely used since their introduction in the year 2000. Typically, they contain a small layer of hydrogen peroxide on a plastic strip. These strips can whiten the teeth by 1 to 2 shades after twice daily applications for 14 days [2]. Their whitening effectiveness correlates with the concentration of $\mathrm{H} 2 \mathrm{O} 2$ that they contain [12].

A number of studies have evaluated the impact of different concentrations of hydrogen and carbamide peroxide on gingival health and tooth sensitivity. Generally, whitening effects of the 2 compounds are reported to be comparable at concentrations of $20 \%$ and $5.3 \%$ respectively [14]. A number of studies indicate that home-bleaching gel containing carbamide peroxide at a concentration level of $10 \%$ is relatively safe [14-17]. However, other researchers have reported considerable concerns about the safety of using hydrogen peroxide products even at low concentrations [18-21]. A strong correlation between higher whitening performance and higher sensitivity from the use of whitening strips was postulated [22].

According to a study published in 2003, 7-23\% of subjects developed gingival irritation and $12-19 \%$ developed dental sensitivity after the use of Crest $^{\oplus}$ 3D WHITE ${ }^{m}$ Whitestrips ${ }^{\text {Tw }}$ [23]. Two other studies reported the development of dental sensitivity ranging from $20-40 \%$ and gingival irritation in $30-70 \%$ of subjects using the whitening strip [23-24]. In two additional studies, Karpinia et al reported 26\% sensitivity and $14 \%$ gingival irritation in one study and $17 \%$ sensitivity and $31 \%$ irritation in another study after use of different whitening strips $[25,26]$. Thus, in order to minimize risks and maximize benefits, patients are welladvised to involve dental professionals as they establish their individual tooth bleaching plans [3].

It is interesting to note that some research has identified improved gingival and plaque indices after applying night guard bleaching formulations [27]. Other literature reports that $10 \%$ carbamide peroxide formulations from 3 different products inhibited select organisms from growing on the surface of the teeth [28]. This might be due to potential antibacterial effects of bleaching products, or perhaps patients might become motivated to take better care of their teeth and improve their oral hygiene as the appearance of their teeth improves from the bleaching process.

Over all, this study demonstrated that the use of a novel whitening strip can potentially mitigate the symptoms of dental sensitivity and gingival irritation that can result from applying bleaching products. However, additional and larger, controlled studies over longer periods of time are needed to more closely evaluate product effects after midand long-term clinical use.

\section{Conclusion}

This in-vivo study determined that a novel whitening strip is very well tolerated after daily use over 10 days. Its side effects were minimal, with lower gingival irritation compared to a commonly used control product. Further studies are required to evaluate and characterize the mid- and long-term effects this novel whitening strips.

\section{Conflict of Interest Statement}

No conflict of interest

\section{Author Contributions Statement}

Angel Emmanuel Rodriguez

Concept/Design, data collection, drafting article, final approval.

Janet Ajdaharian

Concept/Design, data collection, drafting article.

\section{References}

1. Anderson MH (1991) Dental bleaching. Curnt Opin in 12:185-191.

2. Carey CM (2014) Tooth Whitening : What We Now Know. J Evid Based Dent Pract 14: 70-76.

3. Sulieman MA ('2008) An overview of tooth-bleaching techniques: chemistry, safety and efficacy. Periodont 48: 148-169.

4. Haywood VB (1992) History, safety and effectiveness of current bleaching techniques and application of the night guard vital bleaching technique. Quintessence Int 27: 471-488.

5. Haywood VB, Heymann HO (1989) Night guard vital bleaching. Quintessence Int 20: 173-176.

6. Fasanaro TS (1992) Bleaching teeth: history, chemicals, and methods used for common tooth discolorations. J Esth Dent 4: 71-78.

7. AL-Mansour KA, AL-Qussier AM (2015) The effect of $10 \%$ carbamide peroxidbleaching gel on the microhardness of IPS empress direct: An in-vitro study. Pak Oral Dent J 35: 504-508. 
Citation: Rodriguez AE, Ajdaharian J (2017) Effects of Two Dental Whitening Strips on Dental Sensitivity and Gingival Health. Dentistry 7: 451. doi:10.4172/2161-1122.1000451

8. Polydorou O, Hellwig E, Auschill TM (2006) The effect of different bleaching agents on the surface texture of restorative materials. Oper Dent 31: 473-480.

9. Yu H, Zhang CY, Cheng SL, Cheng H (2015) Effects of bleaching agents on dental restorative materials: A review of the literature and recommendation to dental practitioners and researchers. J Dent Sci 89: 425-429.

10. Demarco FF, Meireles SS, Masotti AS (2009) Over-the-counter whitening agents: a concise review. Braz Oral Res 23 : 64-70.

11. Gerlach RW (2000) Shifting paradigms in whitening: intoduction of a novel system for vital tooth bleaching. Compend Contin Educ Dent 21: S4-S9.

12. Serraglio CR, Zanella L, Dalla-Vecchia KB, Rodrigues-Junior SA (2016) Efficacy and safety of over-the-counter whitening strips as compared to homewhitening with $10 \%$ carbamide peroxide gel-systematic review of RCTs and metanalysis. Clin Oral Investig 20: 1-14.

13. Li Y (2011) Safety controversies in tooth bleaching. Dent Clin North Ame 55 255-263.

14. Hasson $\mathrm{H}$, Ismail Al, Neiva G (2006) Home-based chemically-induced whitening of teeth in adults. Cochrane Database Syst Rev 4: 1-43.

15. Zalkind M, Arwaz JR, Goldman A, Rotstein I (1996) Surface morphology changes in human enamel, dentin and cementum following bleaching: a scanning electron microscope study. Endod Dent Traumatol 12: 82-84.

16. Leonard RH Jr, Garland GE, Eagle JC, Caplan DJ (2002) Safety issues when using a $16 \%$ carbamide peroxide whitening solution. J Esthet Restor Dent 14 : 358-367.

17. Sulieman M, Addy M, MacDonald E, Rees JS (2004) A safety study in-vitro for the effects of an in-office bleaching system on the integrity of enamel and dentine. J Dent 32: 581-590.
18. Seghi RR, Denry I (1992) Effects of external bleaching on indentation and abrasion characteristics of human enamel in vitro. J Dent Res 71: 1340-1344.

19. Bitter NC (1990) A scanning electron microscopy study of the effect of bleaching agents on the enamel. A preliminary report. J Prosthet Dent 67: 852-855.

20. Bitter NC, Sanders JL (1993) The effect of four bleaching agents on the enamel surface: a scanning electron microscopy study. Quintessence Int 24: 817-824.

21. McCaslin AJ, Haywood VB, Potter BJ, Dickinson GL, Russell CM (1999) Assessing dentin colour changes from night guard vital bleaching. J Am Dent Assoc 130: 1485-1490.

22. Shannon H, Spencer P, Gross K, Tira D (1993) Characterisation of ename exposed to $10 \%$ carbamide peroxide bleaching agents. Quintessence Int 24 39-44.

23. Gerlach RW, Barker ML, Sagel PA (2001) Comparative efficacy and tolerability of two direct-to-consumer tooth whitening systems. Am J Dent 14: 267-272

24. Gerlach RW, Zhou X (2002) Comparative clinical efficacy of two professional bleaching systems. Compend Contin Educ Dent 23: 35-41 22.

25. Karpinia KA, Magnusson I, Sagel PA, Zhou X, Gerlach RW (2002) Vita bleaching with two at-home professional systems. Am J of Dent 15: 13A-18A.

26. Karpinia K, Magnusson I, Barker M, Gerlach RW (2003) Clinical comparison of two self-directed bleaching systems. J Prost 12: 242-248.

27. Reinhardt JW, Eivins SC, Swift EJ (1993) Clinical study of nightguard vital bleaching. Quintessence Int 24: 379-384.

28. Bentley CD, Leonard $\mathrm{RH}$, Crawford JJ (2000) Effect of whitening agents containing carbamide peroxide on carcinogenic bacteria. J Esthet Dent 12: 33-37. 